\title{
Use of Electrochemical Impedance Spectroscopy (EIS) to monitoring the corrosion of reinforced concrete
}

\section{Uso da Espectroscopia de Impedância Eletroquímica (EIE) para monitoramento da corrosão em concreto armado}
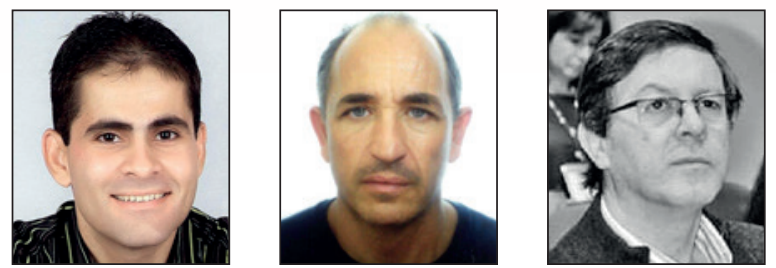

D.V. RIBEIRO a verasribeiro@hotmail.com

C.A.C. SOUZA caldassouza@hotmail.com

J.C.C. ABRANTES a jabrantes@estg.ipvc.pt

\begin{abstract}
Electrochemical techniques are among the most commonly techniques used for the evaluation and study of corrosion in reinforced concrete, including electrochemical impedance spectroscopy (EIS). Electrochemical impedance spectroscopy (EIS) is a powerful technique for characterizing a wide variety of electrochemical systems and for determining the contribution of electrode or electrolytic processes in these systems. The analysis of EIS results on samples of concrete is highly complex due to overlapping arcs from simultaneous phenomena and noise measurement, of course, associated with the heterogeneity of the samples and that complicate the analysis considerably. Thus, this paper proposes a new form of analysis based on the characteristic relaxation angular frequency, w, of each phenomenon and associating the typical capacitances and frequencies.
\end{abstract}

Keywords: corrosion, spectroscopy, concrete, durability, electrochemical techniques.

\section{Resumo}

Entre as técnicas mais utilizadas para a avaliação e estudo da corrosão em concreto armado estão as técnicas eletroquímicas, entre elas a espectroscopia de impedância eletroquímica (EIE). A EIE é uma técnica poderosa para a caracterização de uma grande variedade de sistemas eletroquímicos e para a determinação da contribuição de processos individuais de eletrodo ou eletrólito nestes sistemas. A análise dos resultados de EIE em amostras de concreto armado é de alta complexidade, devido à sobreposição de arcos provenientes de fenômenos simultâneos e a ruídos da medida, associados, evidentemente, à heterogeneidade das amostras e que dificultam de forma considerável esta análise. Assim, o presente trabalho propõe uma nova forma de análise, baseada na frequência angular de relaxação característica, w, de cada fenômeno e associando às capacitâncias e frequências típicas.

Palavras-chave: corrosão, espectroscopia, concreto, durabilidade, monitoramento. 


\section{Introduction}

The term "corrosion of reinforced concrete" refers not only to the reinforcement corrosion problems, but also to conditions of greater or lesser rebar protection by concrete itself.

The protection of the steel by concrete is done in two ways: by a physical barrier, by the covering layer and due to chemical action that results from typical pH of concrete to allow the development of a passivation film on the rebar. Despite this dual protection, there are several factors or conditions that lead to the development of the corrosion process in the concrete, such as reduced coating thickness, low resistance of the concrete coating to penetration of $\mathrm{CO}_{2}$, water and salts, poor compaction or vibration of concrete, presence of contaminants salts or gases such as $\mathrm{SO}_{2}$ or $\mathrm{CO}_{2}$, presence of sulfate-reducing bacteria, reduced amount of cement or elevated water/cement ratio.

The corrosion process in reinforced concrete is a "camouflaged" phenomenon, that is, the first signs of corrosion only appear long after the process began and spread, and therefore, their early identification is very difficult.

Several techniques can be employed for evaluation and study of corrosion in reinforced concrete, and among the most used are the electrochemical techniques. These techniques, besides analyze corrosion as a electrochemical phenomenon and therefore present greater reliability, have the advantage of being fast and not igniting serious damage to the structure at the time of application; in addition it can be used both in the laboratory and in the field.

Electrochemical impedance spectroscopy (EIS) is a powerful technique for characterizing a wide variety of electrochemical systems and for determining the contribution of electrode or electrolytic processes in these systems. It can be used to investigate the dynamics of linked or mobile charges on the volume of interface regions or any liquid or solid material, and assumes that a more or less elaborate circuit can represent the behavior of the steel within the concrete. According to MONTENOR [1], the impedance of an electrical circuit is the measure of its opposition to an electrical signal (potential or current). It is a combination of passive elements of an electrical circuit: resistance, capacitance and inductance. The EIS technique works in the frequency domain and is based on the concept that an interface can be seen as a combination of passive electrical circuit elements, i.e., resistance, capacitance and inductance. When an alternating current is applied to these elements, the resulting current is obtained using Ohm's law. However, due to the concrete heterogeneity, the analysis results of EIS become very difficult because there is a large overlap of arches from simultaneous phenomena and the measurement noise. This study aims to present an alternative of analysis to this powerful technique.

\section{The Electrochemical Impedance Spectroscopy (EIS)}

The principle of this technique is to apply an alternating signal of small amplitude (5 to $20 \mathrm{mV}$ ) to an electrode (rebar) inserted into an electrolyte (concrete), as observed in Figure 1.

The initial disturbance (applied) and the response of the electrode is compared by measuring the phase shift of the current and voltage components and by the measurements of their amplitudes. This can be done in the time domain or in the frequency domain, using a spectrum analyzer or frequency response analyzer, respectively. Importantly, the initial disturbance is a disturbance potential $(\Delta \mathrm{E})$ of sinusoidal type, which must be imposed at steady state of the system and the electrode response is a current $(\Delta \mathrm{I})$, also sinusoidal, but with a difference of phase $(\Phi)$ to the applied signal [2]. Therefore, the impedance which is represented by $Z$, measures the relationship between $\Delta \mathrm{E}$ and $\Delta \mathrm{l}$.

The EIS technique works in the frequency domain and is based on the concept that an interface can be seen as a combination of passive electrical circuit elements, i.e., resistance, capacitance and inductance. When an alternating current is applied to these elements, the resulting current is obtained using Ohm's law.

For the steel/concrete system, information on several parameters can be obtained, e.g., the presence of surface films, characteristics

\section{Figure 1 - Apparatus for measuring the corrosion process by electrochemical impedance spectroscopy (EIS)}
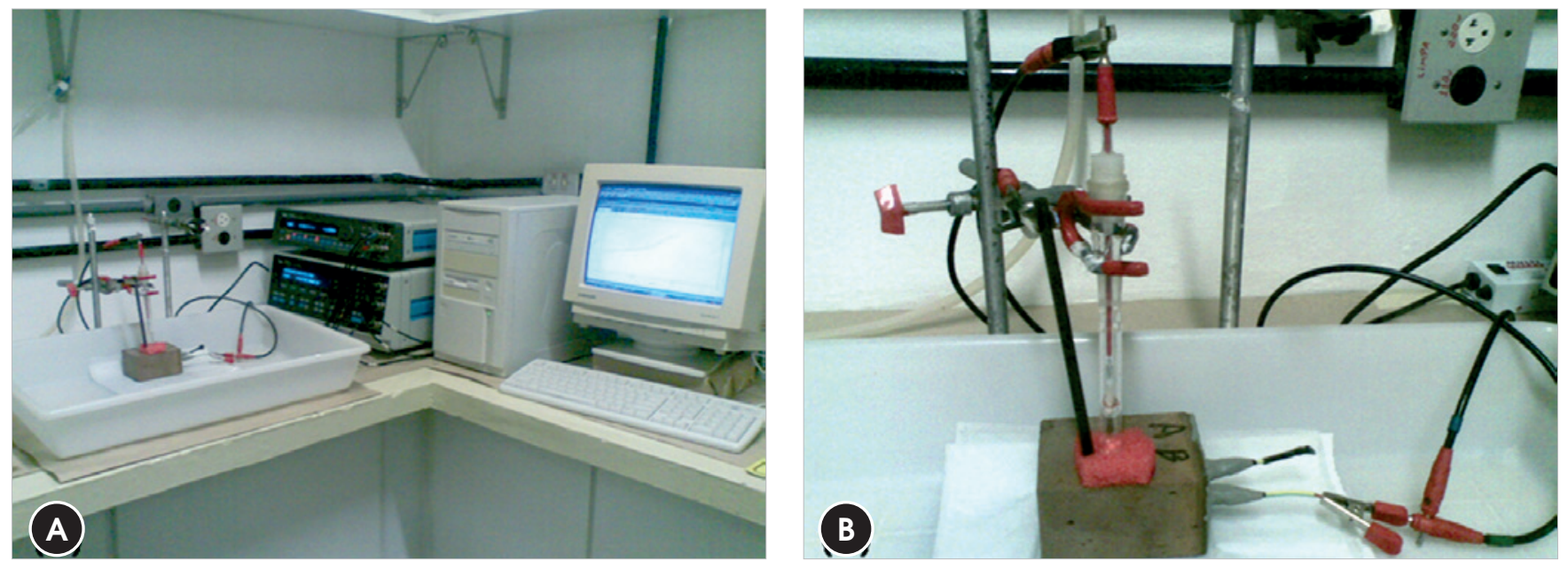


\section{Figure 2 - Nyquist diagram and its equivalent circuit, showing the effect of diffusional impedance (SILVERMAN apud FREIRE (5))}
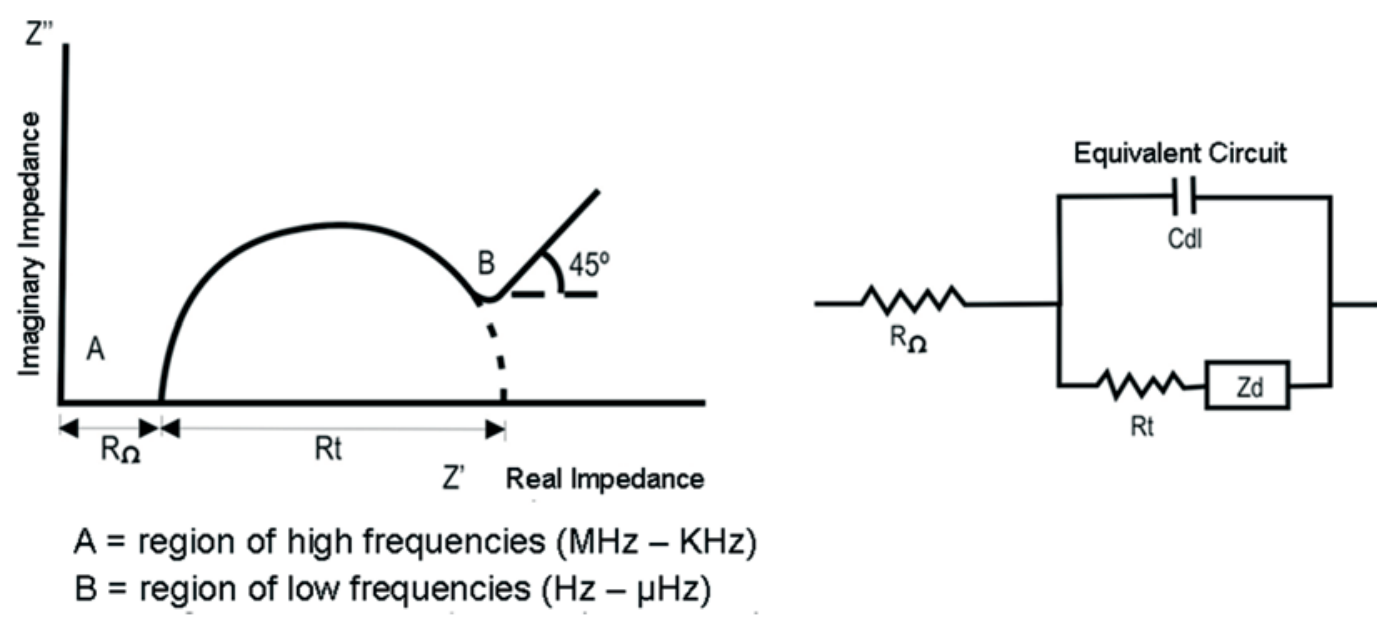

Rt

of the concrete, interfacial corrosion, and mass transfer phenomena. However, interpreting the results may be difficult and the use of an equivalent circuit, which can change according to the conditions of the steel, makes the technique more suitable for laboratory studies [1]. The main advantages of EIS are:

It provides information about the corrosion kinetics.

- It is an accurate and reproducible technique suitable for highly resistive environments such as concrete.

- It provides data about the electrochemical control mechanism, indicating if corrosion occurs by activation, concentration or diffusion.

It characterizes the state of the rebar and the morphology of the corrosion.

- It is a non-destructive and non-perturbative technique, since the signals applied are of small amplitude, so the corrosion potential is not changed; and

- It allows for monitoring of the evolution of the passive or active state over time.

\subsection{Interpretation of results}

The interpretation of the EIS measures is usually done by the correlation between the impedance data and the equivalent circuit representing the physical processes taking place in the system under investigation or through graphics.

The graph $Z=Z^{\prime}+j Z^{\prime \prime}$ real part and imaginary part, respectively, measured at different frequencies is called "Nyquist diagram", impedance diagram or impedance spectrum. The other representation is called "Bode diagram" which shows the logarithm of the impedance modulus $(\log |Z|)$ and the phase displacement as function of the logarithm of frequency.

The Nyquist diagram (Figure 2), also known as Argand representation or Colo-Cole representation, consists of a series of points, each of which represent the magnitude and direction of the impedance vector of a particular frequency [3]. The diagram is a complex plane of Cartesian coordinates, where the abscissa is the real part (resistive terms) and the ordinate is the imaginary part (capacitive or inductive terms). Impedance data represented on the Cartesian plane under a wide range of frequencies $(100 \mathrm{KHz}$ to $10 \mathrm{mHz}$, usually $10 \mathrm{KHz}$ to $0.1 \mathrm{mHz}$ ) generate typical configurations according to the predominant electrochemical mechanism. Figure 2 shows a typical Nyquist diagram, and its equivalent circuit.

After built the Nyquist diagram, the extrapolation of the right side of the semicircle is done to find the horizontal axis. The diameter of the semicircle extrapolated in the Nyquist diagram represents the charge transfer resistance $R_{t}$ equivalent to the polarization resistance $\left(R_{p}\right)$ [2]. Thus, the larger the diameter of the semicircle the higher the resistance, $R_{p}$, and hence, the lower the corrosion rate [4].

One of the difficulties of the impedance technique clearly evidenced in the Nyquist diagram is the characterization of an essentially passive rebar. In this state, the charge transfer along the rebar, which denotes a corrosion process, is very small. Thus, the capacitive semicircles or arcs of charge transfer in the electric double layer are poorly developed, compromising data interpretation [2].

The Bode diagram consists of a orthogonal axes plane, in which they have, on the ordinate axis, two quantities: the logarithm of the impedance $(\log |Z|)$ in ohms $(\Omega)$ and the phase angle $(\Phi)$ in degrees; and the abscissa axis there is the logarithm of the angular frequency $(\log \omega)$ with $\omega$ in radians per second ( $\mathrm{rad} / \mathrm{sec}$ ). It can also represent the abscissa the logarithm of the frequency $(\log \mathrm{f})$, with $\mathrm{f}$ in Hertz. With the configuration log $\omega$ versus $|\mathrm{Z}|$ can be determined $\mathrm{R} \omega$ and Rt, according to Figure 3; and by the phase angle versus log $\omega$ it is possible to determine the capacitance of the electrical double layer $\mathrm{Cdl}$, knowing that:

$$
\mathrm{Rp}=2 \cdot|\mathrm{Z}| \cdot \operatorname{tg} \max
$$


Figure 3 - Bode diagram representing the impedance (modulus and phase angle) of an electrochemical corrosion system as a function of the angular frequency (3)
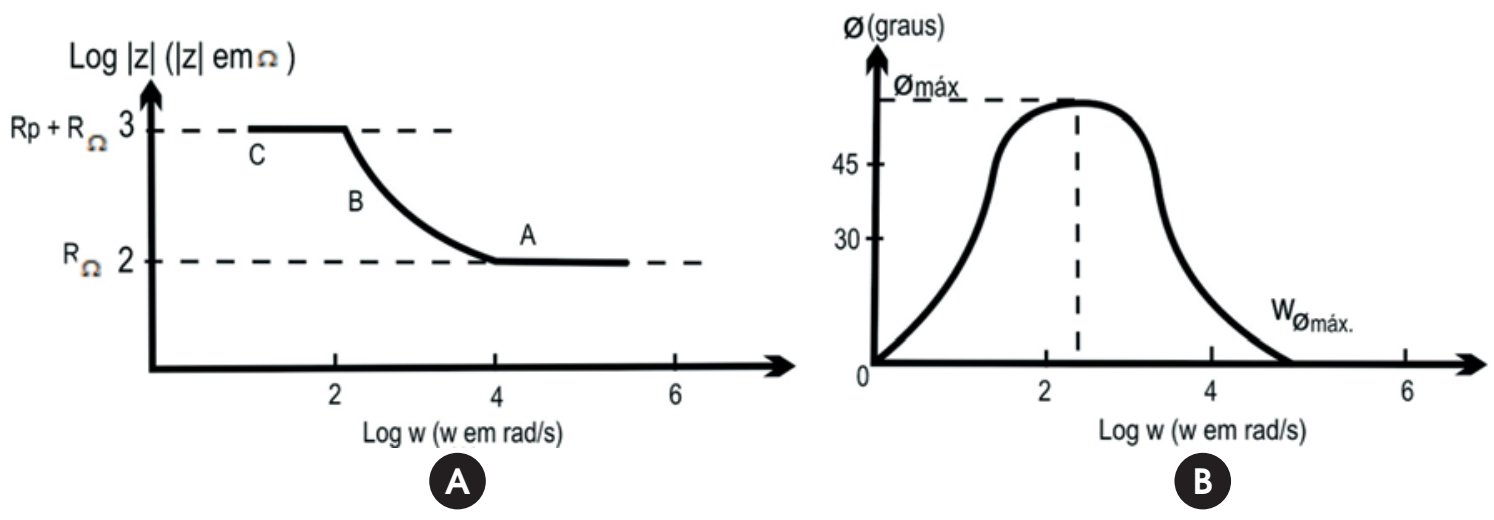

B

$$
\omega_{\phi_{\text {max }}}=\frac{1}{C_{d l} \cdot R_{P} \cdot\left(1+R_{P} / R_{\Omega}\right)^{1 / 2}}
$$

, where: $\phi_{\max }$ is the maximum phase angle of the system impedance, $\omega_{\phi \max }$ is the angular frequency corresponding to the $\phi_{\max }$ and $|\mathrm{Z}|$ is the impedance module matching to $\phi_{\max }$

In the Bode diagram there are two clearly different regions: the high frequency region (Figure $3 A$, the region $A$ ) characterized by the presence of passivation films and other types of coating on the rebar; the medium frequency region (Figure $3 \mathrm{~A}$, region $\mathrm{B}$ ) which reflects the change of electrical conductivity of the coating during exposure in a corrosive environment and, finally, the low-frequency region (Figure $3 \mathrm{~A}$, region $\mathrm{C}$ ) where the corrosion reaction on the metal/coating interface can be studied [2].

\subsection{Equivalent circuits}

A major problem in using equivalent circuits is deciding which specific equivalent circuit, among many possibilities, should be used. A corrosion process involves several simultaneous physical pro-

Figure 4 - Equivalent circuit for concrete proposed by John et al. (6). Rc: concrete strength; Rf and Cf: resistance and capacitance of the film; $\mathrm{Zd}$ : diffusion impedance; Rct and Cdl: charge transfer resistance and double layer capacitance

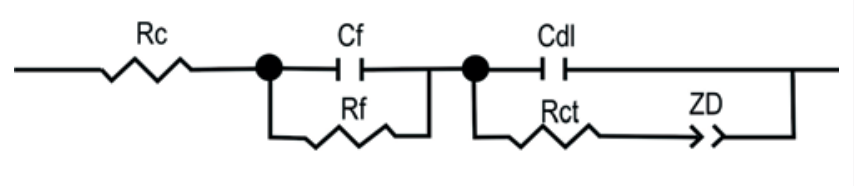

cesses and, therefore, the equivalent circuit is composed of various circuit elements. However, one process to another, the circuit elements may also vary the manner in which they are interconnected. In Table 1 is shown the correlation between physical processes and electrical circuit elements used in EIS.

The pioneers of the use of IES to monitor corrosion in reinforced concrete was JOHN et al.[6]. These authors proposed the circuit described in figure 4 and applied the IES on concrete samples immersed in seawater. The impedance at low frequency response was related to the charge transfer process, considering that the response at high frequencies was attributed to the presence of a surface film.

Another alternative for the interpretation of the steel/concrete system was proposed by MACDONALD et al. apud FREIRE [5]. The authors described a system response based on a model of transmission lines as shown in Figure 5, where $\mathrm{R}$ is the resistance bar/ segment; $\mathrm{R} i$ is the resistance concrete/segment; $\mathrm{Zj}$ interfacial impedance bar/concrete.

This model assumes that the electrical properties of steel and concrete are purely resistive, with the resistivity concrete being

\section{Table 1 - Properties of the components of the composite beam}

\begin{tabular}{|cc|}
\hline $\begin{array}{c}\text { Physical process } \\
\text { Charge transfer }\end{array}$ & $\begin{array}{c}\text { Electrical circuit element } \\
\text { Electrical double layer }\end{array}$ \\
$\begin{array}{c}\text { Dielectric surface layers } \\
\text { (organic coatings } \\
\text { and oxides })\end{array}$ & Capacitor, Cdl \\
\hline Adsorption & 14.700 \\
\hline Mass transport & Capacitor, C \\
\hline
\end{tabular}




\section{Figure 5 - Transmission lines model described for reinforced concrete} and proposed by MACDONALD et al. apud FREIRE (5)

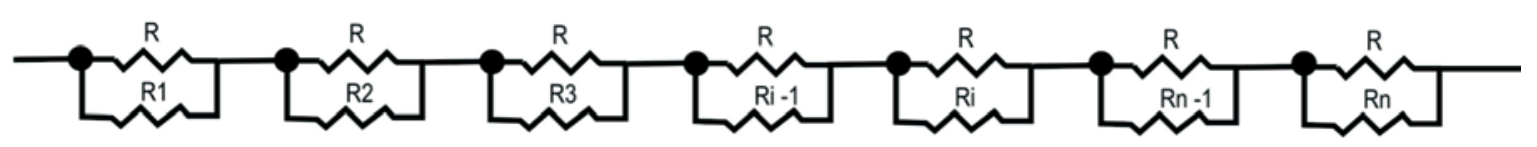

dependent on the position due to the heterogeneity of matrix. Moreover, the model assumes that the interface is reactive due to the capacitor pseudocapacitor and diffusional components existence. The models show that the real part and the imaginary part of the impedance response and the phase angle to low frequencies allow to detect and locate the corrosion.

DHOUIBI-HACHANI et al. [7] proposed another approach shown in Figure 6, which includes the following items: (i) the products formed directly on the steel surface, (ii) products which are the result of reaction between corrosion products and the cement paste and (iii ) the depth of the concrete cover.

The model shows a good agreement between the experimental data and the calculated Nyquist diagrams, where Rc is the concrete strength; $R_{1}$ represents the resistance of the corrosion products formed in the rebar; $C_{1}$ and $R_{4}$ are the capacitance and the dispersion resistance (frequency dependent); $R_{3}$ is the steel interface resistance; $\mathrm{R}_{2}$ and $\mathrm{C}_{2}$ : capacitance and dispersion resistance due to homogeneity of the products on the metal surface.

Sometimes, despite the increasing development in the interpretation of the EIS spectra, they reveal behavior difficult to explain. These include the presence of low-frequency branches, semicircles displaced and high frequency effects. The first effect led to the introduction of a Warburg element (W) in series with the charge transfer resistance due to the replies of faradaic processes that occur at the interface. These effects explain why the steady state sometimes cannot be achieved with conventional direct current techniques (DC), even after a long waiting time. They also explain the long time constant observed in the impedance spectra at low frequencies and the need to extrapolate the polarization resistance values [1].

Figure 6 - Equivalent circuit for concrete proposed by DHOUIBI-HACHANI et al. (7)

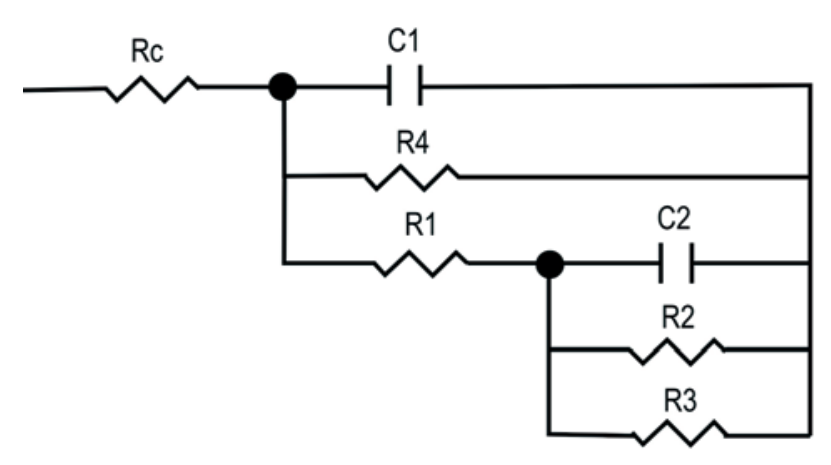

The presence of displaced semicircles suggests a non- ideal behavior of the capacitor, leading to the introduction of the constant phase element (CPE) to the equivalent circuits. SAGUES et al. [8] introduced this element in systems that show simple polarization processes. They concluded that some improvement is obtained if the CPE is used instead of an ideal capacitor. In another study, FELIU et al. [9] have proposed a more complex system and introduced a CPE and diffusion parameters in the equivalent circuit as shown in Figure 7. This has led to an increase in accuracy of determination of polarization resistance when this was possible.

The equivalent circuit proposed by Randles in Figure 8, has a wide application in many electrochemical systems. In this circuit, Re represents the solution and the corrosion product film resistances, which is also known, according SAGUES et al. [8] as the ohmic resistance of the electrolyte between the sensory point of reference electrode voltage and the electrode/electrolyte interface. $R_{t}$ and $C_{d l}$ represent the corrosion interface: $C d l$ is the double electric layer capacitance resulting from ions and water molecules adsorbed, due to the potential difference between the electrode suffering corrosion and the solution (or electrolyte), and Rt is the resistance to charges transfer, determining the corrosion rate of reaction and is a measure of electric charges transfer through the electrode surface. In a system controlled by activation, Rt is the portion measured by the polarization resistance technique, that is, $\mathrm{Rt}$ is equivalent to $\mathrm{Rp}$.

In a recent study, MARTíNEZ \& ANDRADE [10] added two RC time constants, used when necessary, as can be seen in Figure 8B .

For the steel/concrete interface, the equivalent circuit is not as simple as the Randles circuit. The model proposed by CRENTSIL apud MACHADO [17] relates a semicircle at high frequencies to concrete properties. The second semi-circle, at intermediate frequencies, is attributed to the formation of corrosion products.

Figure 7 - Equivalent circuit with introduction of CPE, proposed by FELIU et al. (9).

$\mathrm{Re}=$ electrolyte resistance; $\mathrm{Rf}=$ charge transfer resistance; $\mathrm{CPE}=$ constant phase element; ZD = Warburg diffusion

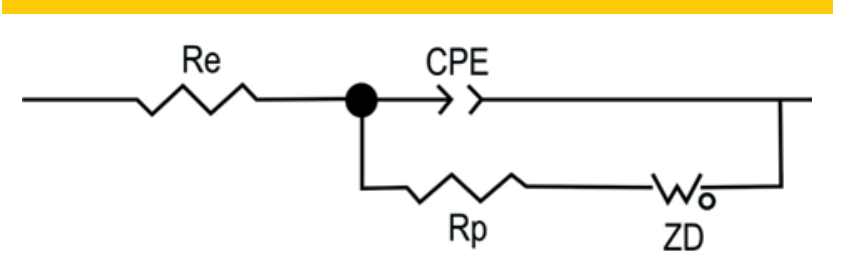




\section{Figure 8 - (A) Simple equivalent circuit type Randles and; (B) Randles circuit modified with two time constants (10)}

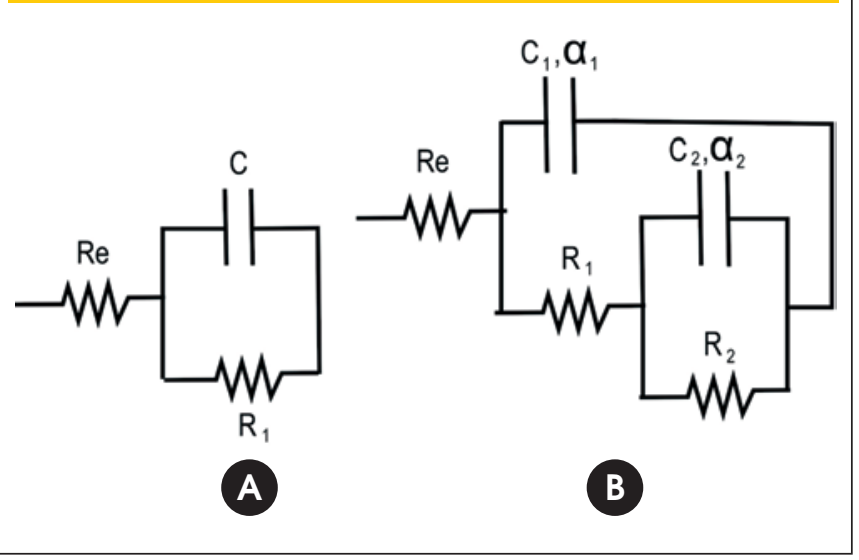

At low frequencies, the presence of a semicircle and a characteristic straight line with slope equal to one (1) involves the superposition of two effects. concrete and the different constituents of the solid phase;

- Medium frequencies $(\mathrm{KHz}-\mathrm{Hz})$ : the faradaic processes presents an answer. Typical capacitances are of the order of $\mathrm{mF} /$ $\mathrm{cm}^{2}$. It may be found more than a time constant when there is a localized attack. The carbonated concrete produces a semicircle flattening in the Nyquist diagrams;

- Low frequencies $(\mathrm{Hz}-\mathrm{mHz})$ : redox reactions $\mathrm{Fe}^{2+}$ « $\mathrm{Fe}^{3+}$ may occur, depending on the potential. The measured capacitances are in the order of $\mathrm{mF} / \mathrm{cm}^{2}$. Diffusion phenomena may appear through the passive layer.

Based on these mentioned frequencies, CHRISTENSEN et al. $[11,12]$ proposed a correlation between the corrosion phenomenon and the equivalent circuit and it is widely accepted in several researches. The equivalent circuit proposed by these authors is shown in Figure 10.

The equivalent diagram, presented in Figure 10, is associated to an "apparent offset" resistance $\left(R_{0}\right)$ in series with the concrete $\left(R_{2} Q_{2}\right)$ and connected also in series to the electrode $\left(R_{e} Q_{e}\right)$. These elements are best viewed by Nyquist diagram shown in Figure 11. The variables shown in Figure 11 can be interpreted as:

- Electrode Resistance $\left(R_{\mathrm{e}}\right)$ : The electrode resistance (in this case the rebar) is represented by the semicircle radius that

Figure 9 - Schematic representation of (A) steel/concrete interface; (B) equivalent circuit ( $m$ = matrix; $f=$ film) and; $(C)$ corresponding Nyquist diagram (4)
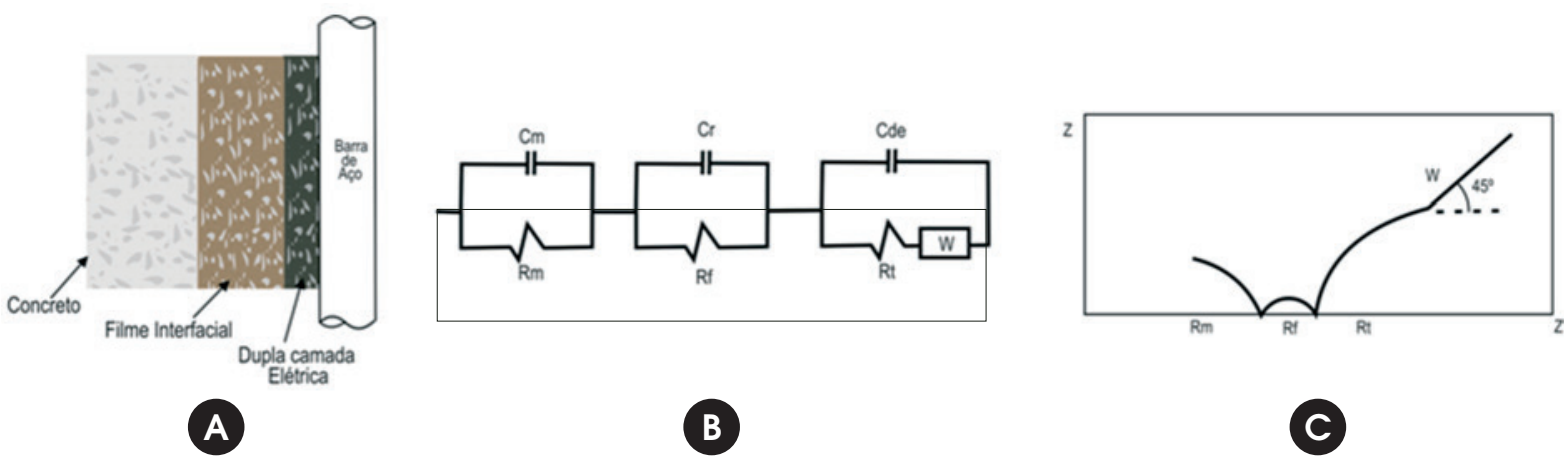

B

C)

According to MACHADO [17], the semicircle reflects the corrosion kinetics effect and the straight is related to the diffusion of oxygen through the oxide layer, represented by an Warburg element, W. Figure 9 shows a schematic representation of steel/ concrete interface, the equivalent electric circuit and the corresponding Nyquist diagram.

Then, it is possible to associate these three regions of the diagram to the mortar properties (matrix, $\mathrm{m})$, to the interfacial film $\left(\mathrm{Ca}(\mathrm{OH})_{2}\right.$ layer) and to an interface region, with charges transfers and the double layer capacitance (interstitial solution/steel interface).

In simple terms, it's possible to identify three frequency bands, in which different processes have an impedance response [4]:

- High frequencies $(\mathrm{MHz}-\mathrm{KHz})$ : the electrolyte presents an answer. The capacitances are of the $\mathrm{pF} / \mathrm{cm}^{2}$ order. More than a time constant may appear due to the moisture content of the appears in the low frequency regions. At first, the smaller this distance, the greater the corrosion;

Figure 10 - Equivalent circuit for concrete proposed by CHRISTENSEN et al. (11)

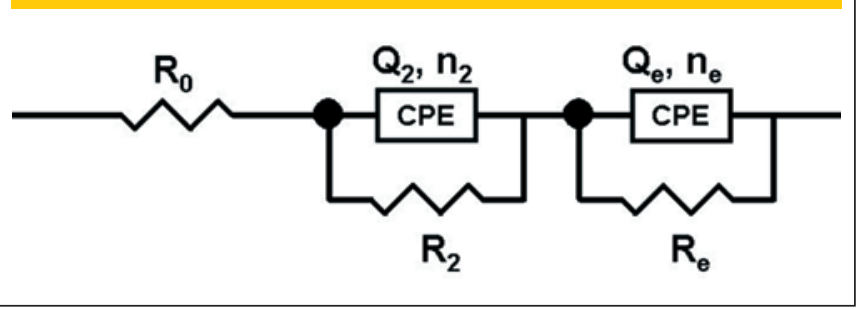


Figure 11 - (A) Nyquist diagram proposed for reinforced concrete and; (B) Expansion of the high frequency region of the previous diagram

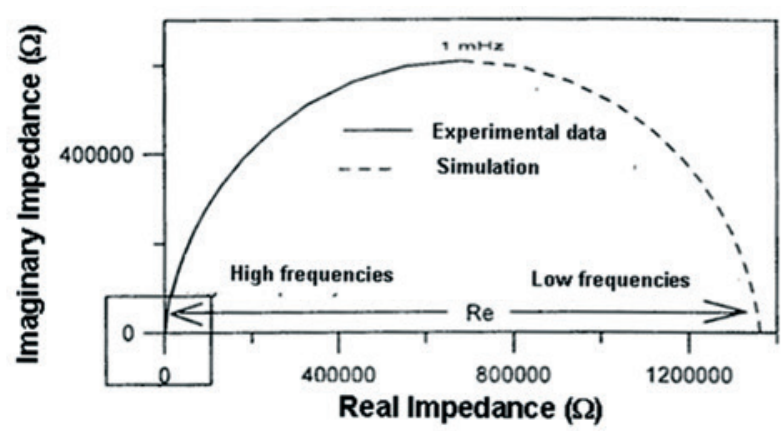

(4)

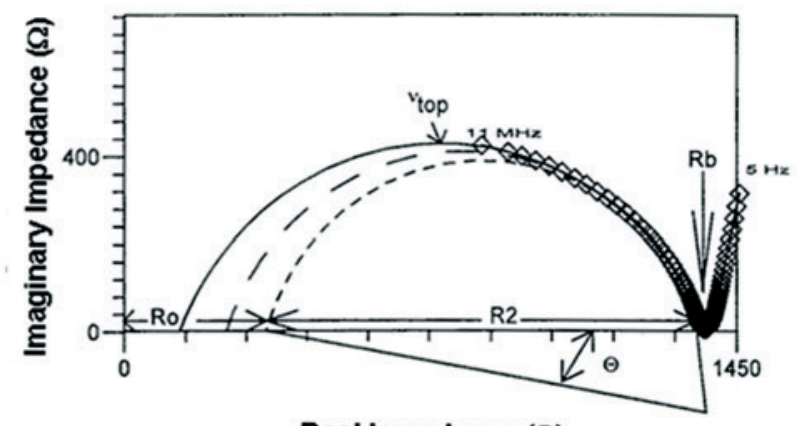

Real Impedance $(\Omega)$

B
- Cement matrix of the Resistance $\left(R_{b}\right)$ : This value is easily detected in the impedance spectra corresponding to the intersection between the arcs regarding to electrode and the cement body itself;

- Offset Resistance $\left(R_{0}\right)$ : It's a "initial"resistance, without much interest for the process and no apparent physical meaning. In practical terms it can be neglected, considering $R_{b}=R_{0}+R_{2}$.

- Depression angle $(\theta)$ : Often expressed by the arc depression factor, $n[n=1-(2 \theta / \pi)]$, is related to the specimen imperfections, predominantly to the pore size distribution. The closer to zero (n close to 1), behaves as a perfect capacitor in the system.

As can be seen, there is a variety of equivalent circuits proposed that suit to different ways to evaluate the different materials used in the production of concrete and is an arduous task to determine an equivalent circuit that fully meets all the phenomena observed in the corrosion process.

\section{Proposed method for the interpretation of EIS results}

The analysis of the EIS results became increasingly complex, due to overlapping phenomena and to noise in the measurement resulting from the heterogeneity of the samples.

In view of these difficulties, we decided to change the way in which the analysis was performed. The basic theory states that these processes have a characteristic angular relaxation frequency, $\mathrm{w}$ (starting from which they no longer respond), which is given by $w=$ $1 / R C$ and which can also be read graphically at the top of the arc of the impedance spectrum [13,14]. Thus, we sought to associate the analyzable arcs with the typical capacitances and frequencies of each phenomenon.

The identified arcs were therefore isolated and related to each of the phenomena and a local analysis was performed, which improved the accuracy. A similar strategy was adopted by VERMOYAL et al. [13] in their studies. To this end, we used the simplified circuit shown in Figure 12.

When arcs are analyzed separately and fitted according to the simplified electrical circuit (Figure 12B), one obtains the following results: the arc resistance ( $\left.R^{\prime \prime}\right)$, the values of the constant phase element (CPE), $Q$, and the " $n$ " index. This index measures the perfection of this element, varying between 0 and 1 , and comes closer to the unit value as the CPE approaches a perfect capacitor,

Figure 12 - Equivalent electrical circuits proposed for the steel-concrete interface, based on (A) a general analysis, and (B) analysis of individual arcs (simplified circuit) proposed by VERMOYAL et al. (13)
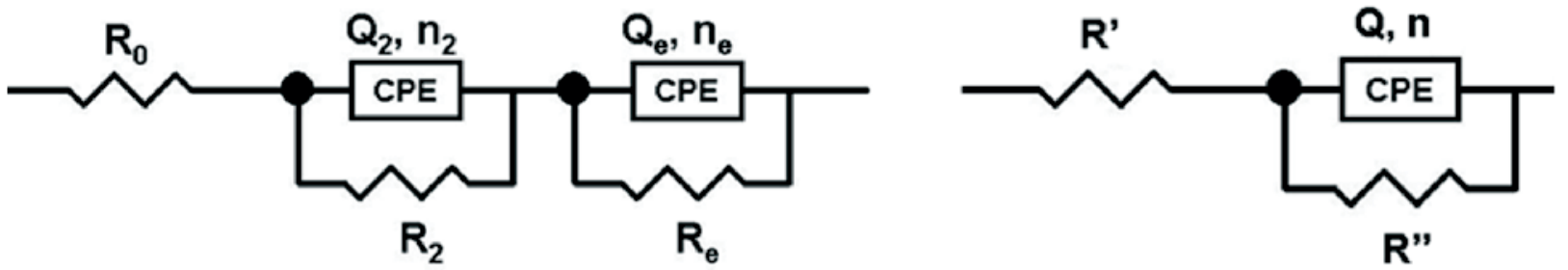

A

B 


\section{Figure 13 - Correlation between the capacitance and characteristic frequency of each phenomena observed by EIS}

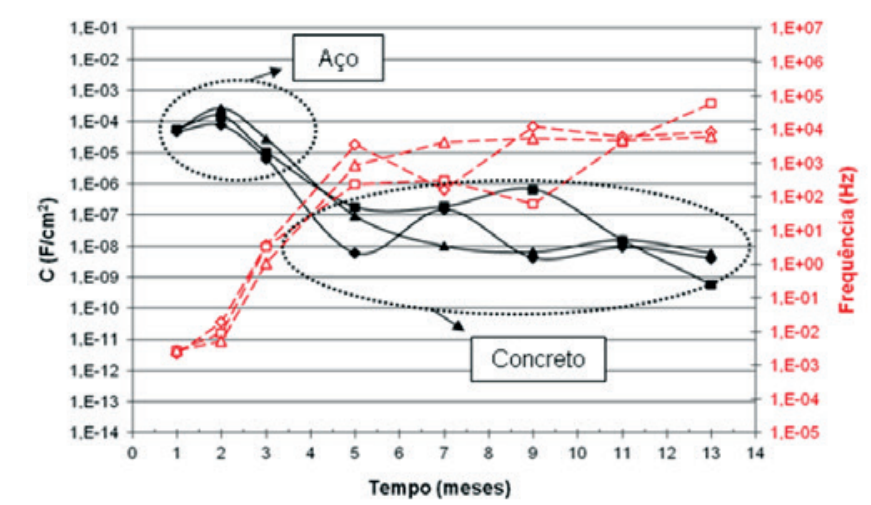

-

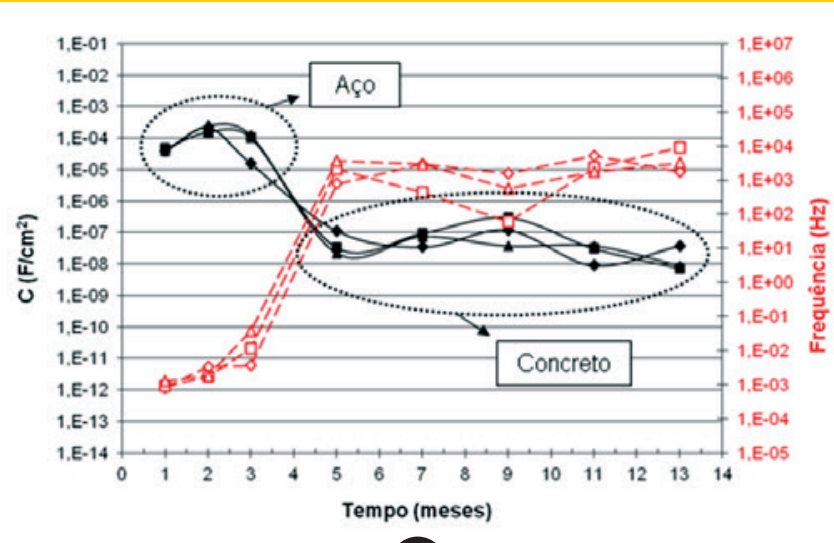

B
C $[4,11,15]$. Thus, the characteristic capacitance, C, can be calculated according to equation (3).

$$
C=Q^{\frac{1}{n}} \cdot R^{\frac{1-n}{n}}
$$

The characteristic frequency (f) associated with this characteristic capacitance is calculated in Hertz, according to equations (4) and (5), where $w=1 / R C[4,14]$.

$$
f(H z)=\frac{w}{2 \pi}
$$

$$
f(H z)=\frac{1}{2 \pi \cdot R \cdot C}
$$

Observing the correlation between the characteristic capacitances and characteristic frequencies calculated for each phenomenon, it can be grouped as follows:

- Low frequencies in the range of $1 \mathrm{mHz}$ to $10 \mathrm{~Hz}\left(10^{-3}-10\right.$ $\mathrm{Hz}$ ) correspond to the electrode resistance $\left(\mathrm{R}_{\mathrm{e}}\right)$ and are thus related to the corrosion phenomenon. The characteristic capacitance of this frequency band ranges from $10^{-6}$ to $10^{-3} \mathrm{~F} / \mathrm{cm}^{2}$.

- Medium frequencies in the range of $100 \mathrm{~Hz}$ to $\mathrm{MHz}\left(10^{2}-10^{6}\right.$ $\mathrm{Hz}$ ) correspond to the concrete resistance $\left(R_{2}\right)$ and are related to the characteristics of the concrete surrounding and protecting the rebar. The characteristic capacitance of this frequency band lies between $10^{-9}$ and $10^{-6} \mathrm{~F} / \mathrm{cm}^{2}$.

- High frequencies above the $\mathrm{MHz}$ range $\left(>10^{6} \mathrm{~Hz}\right)$ are associ- ated with the "offset resistance" $\left(R_{0}\right)$, whose relevance is minor and whose values were neglected in this study.

This correlation between the characteristic capacitances and characteristic frequencies calculated for each phenomenon is shown in Figure 13. It is clearly observed that the characteristic frequencies are very well defined.

From, there, simply that the researcher associate each arch individually to the concrete resistivity $\left(R_{2}\right)$ or the electrode, in the case, the rebar $(R e)$. This association will be based on the frequency at which the phenomenon occurs ( $\mathrm{f}$ ) or on capacitance (C). According to some studies $[4,16]$, the rebar is in the process of corrosion if the diameter of semicircle formed at low frequencies is decreased, as observed in the Nyquist diagram. Therefore, as lower are $R_{e}$ values, more advanced is the corrosion process and the resistance of a typical electrode in a considerable corrosive process is in the order of $\mathrm{K} \Omega$.

\section{Conclusions}

This research led to the following conclusions:

- Electrochemical impedance spectroscopy (EIS) is a highly reproducible and powerful technique. However, its application is limited by the difficulties involved in interpreting EIS data and by the lack of internationally accepted criteria, indicating that this technique still lacks in-depth studies;

- The traditional analysis of the results of EIS, by direct analysis of the equivalent circuit can be very complicated due to the arcs overlapping as a function of the concrete heterogeneity, resulting in errors;

- The processes have an characteristic angular relaxation frequency, $w$ (from which fail to respond), given by $w=1 / R C$, and which can also be graphically read at the top of the impedance spectrum arc;

- The relationship between the arcs observed in the spectroscopy results and the characteristic relaxation frequency proved to be an interesting alternative for the analysis of heterogeneous and complex systems such as reinforced concrete, increasing the accuracy of measurements. 
- It's possible to associate each arch, individually, to the concrete resistivity $\left(R_{2}\right)$ or rebar resistivity $(R e)$, based on the frequency at which the phenomenon occurs (f) or according to its capacitance $(\mathrm{C})$;

- The phenomena involved in reinforcement corrosion and the inherent characteristics of concrete are observed at low $(1 \mathrm{mHz}$ a $10 \mathrm{~Hz})$ and médium $(100 \mathrm{~Hz} \mathrm{a} \mathrm{MHz})$ requencies, respectively. The typical electrode resistance of an advanced corrosion process is the order of $\mathrm{K} \Omega\left(10^{3} \Omega\right)$;

- The phenomena occurring at medium frequencies correspond to the concrete resistance $\left(R_{2}\right)$, being associated to the matrix features that surrounds and protects the rebar and the phenomena that occur at high frequencies (higher than the $\mathrm{MHz}$ range), are associated with "offset" resistance $\left(R_{0}\right)$, of without relevance and presenting negligible values.

\section{References}

[1] MONTEMOR, M. F.; SIMÕES, A.M.P.; FERREIRA, M.G.S. Chloride-induced corrosion on reinforcing steel: from the fundamentals to the monitoring techniques. Cement and Concrete Composites. v. 25, n. 4-5, p. 491-502, 2003.

[2] LANGFORD, P. BROOMFIELD, J. Monitoring the Corrosion of Reinforcing Steel. v.1, n². Construction Repair, p. 32-36, 1987

[3] WOLYNEC, S. Técnicas eletroquímicas em corrosão. São Paulo: EDUSP, 2003. 166 p.

[4] AGUILAR, A.; SAGÜÉS, A.; POWERS, R. Corrosion Rates of Steel in Concrete. ASTM-STP 1065, American Society for Testing and Materials, p. 66-85, 1990.

[5] FREIRE, K.R.R. Avaliação Do desempenho de inibidores de corrosão em armaduras de concreto. Curitiba, 2005. 192p. Dissertação (Mestrado), Universidade Federal do Paraná.

[6] JOHN, D.G.; SEARSON, P.C.; DAWSON, J.L. British Corrosion Journal. v. 16, p. 102, 1981.

[7] DHOUIBI-HACHANI, L.; et al. Comparing the steel-concrete interface state and its eletrochemical impedance. Cement and Concrete Research. v. 26, n. 2, p. 253-266, 1996.

[8] SAGUES, A.A.; KRANC, S.C.; MORENO, E.I. The time-domain response of a corrodyng system with constant phase angle interfacial component: application to steel in concrete. Corrosion Science. v. 37, n. 7, p.1097-1113, 1995.

[9] FELIU, V.; et al. Equivalent circuit for modelling the steelconcrete interface I: experimental evidence and theroretical predictions. Corrosion Science. v. 40, n. 6, p.975-993, 1998.

[10] MARTÍNEZ, I.; ANDRADE C. Application of EIS to cathodically protected steel: tests in sodium chloride solution and in chloride contaminated concrete. Corrosion Science. v. 50, n. 10, p. 2948-2958, 2008.

[11] CHRISTENSEN, B.J.; et al. Impedance spectroscopy of hydrating cement-based materials: measurement, interpretation, and application. Journal of the American Ceramic Society, n. 77, v. 11, p. 2789-2804, 1994.

[12] CHRISTENSEN, B.J.; MASON, T.O.; JENNINGS H.M.; Influence of silica fume on the early hydration of Portland cements using impedance spectroscopy. Journal of the American Ceramic Society, n. 75, v. 4, p. 939-945, 1992.

[13] VERMOYAL, J.J.; FRICHET, A.; DESSEMOND, L.; HAMMOU, A. AC impedance study of corrosion films formed on zirconium based alloys. Electrochimica Acta, v. 45, n. 7, p. 1039-1048, 1999.

[14] MAIA, L.F.; RODRIGUES, A.C.M. Electrical conductivity and relaxation frequency of lithium borosilicate glasses. Solid State lonics, v. 168, n. 1-2, p. 87-92, 2004.

[15] COVERDALE, T.; et al. Interpretation of impedance spectroscopy of cement paste via computer modelling. Journal of Materials Science, v. 30, n. 20, p. 712-719, 1995.

[16] SILVA, F.G. Estudo de concretos de alto desempenho frente à ação de cloretos. 2006. 218p. Tese (Doutorado em Ciência e Engenharia de Materiais) - Área de Interunidades em Ciência e Engenharia de Materiais, Universidade de São Paulo, São Carlos, 2006.

[17] MACHADO, M.A.G.T.C. Inibidores de Corrosão em Concreto Armado contra o ataque de agentes da chuva ácida. São Carlos, 2004. 161p. Tese (Doutorado), Universidade Federal de São Carlos. 